\title{
VENEZUELA 2009: EN MEDIO DE DIFICULTADES AVANZA EL modelo socialista del Presidente Chávez
}

\author{
Venezuela 2009: In the Midst of Difficulties, President Chávez Keeps \\ Pushing Forward his Socialist Model
}

\author{
MARGARITA LÓPEZ MAYA \\ Universidad Central de Venezuela (UCV) \\ LUIS E. LANDER \\ Universidad Central de Venezuela (UCV)
}

\begin{abstract}
RESUMEN
La gestión gubernamental venezolana de 2009 se caracterizó por una intensificación del proceso de transformaciones de la estructura estatal y de las relaciones entre Estado y sociedad, orientadas por el llamado modelo del Socialismo del siglo XXI. Se continuó con la estatización de sectores de la economía, la recentralización del aparato político administrativo del Estado y la sostenida pérdida de autonomía de los poderes públicos a favor del Presidente de la República. El artículo está dividido en cinco partes. En la primera se presentan las principales características del Socialismo del siglo XXI contenidas en el documento oficial titulado Las Líneas Generales del Desarrollo Económico y Social de la Nación 2007-2013, guía de la acción gubernamental. En una segunda parte, se presentan los principales indicadores socioeconómicos del año. La parte tres está dedicada a describir el proceso refrendario realizado el 15 de febrero, que aprobó una enmienda constitucional para permitir la reelección indefinida del Presidente y demás cargos de elección popular. La cuarta parte recoge los principales hitos de la gestión del Ejecutivo Nacional, el principal actor gubernamental. En la quinta y última se señalan las actuaciones más relevantes del Poder Legislativo y se cierra con unas conclusiones.
\end{abstract}

Palabras clave: Venezuela, socialismo del siglo XXI, gobierno, elecciones.

\begin{abstract}
During 2009 President Chavez' administration continued with the transformations of Venezuela's State structures and State-Society relations orientated by the Socialism of the $21^{\text {st }}$ Century Model. In a more intensive way than in prior years sectors of the economy were passed to the State, the recentralization process of the State apparatus kept unfolding and Public Powers continued loosing autonomy to the President of the Republic. This article tackles the complexities of the year through five sections. In the first we describe main features of the Socialism of the 21st Century Model. We do this by revising the official document named Las Líneas Generales del Desarrollo Económico y Social de la Nación 2007-2013, which serves the Government as general policy orientation. Section two presents relevant socioeconomic data of 2009. Section three examines the referendum process that on February 15 resulted in the approval of the Constitutional amendment that allows indefinite elections for the President and all other elected authorities. Section four presents the most important actions taken this year by the National Executive which is today the most important governmental actor. In section five we revise decisions and actions of the rest of the Public Powers to end with conclusions.
\end{abstract}

Key words: Venezuela, 21'st century socialism, government, elections. 
Marcado por los resultados electorales de noviembre 2008 y febrero 2009, la gestión gubernamental de 2009 se caracterizó por una mayor intensificación del proceso de transformaciones de la estructura estatal y de las relaciones entre Estado y sociedad, orientadas por el modelo del Socialismo del siglo XXI. En correspondencia con algunas tendencias ya señaladas en la gestión de 2008 (ver Maingón y Welsh, 2009), pero ahora aceleradas -o para usar el lenguaje oficial radicalizadas-, se continúa con la estatización de sectores de la economía, la recentralización del aparato político administrativo del Estado y la sostenida pérdida de autonomía de los poderes públicos a favor del Presidente de la República. El Presidente Chávez se convierte en el principal protagonista de la gestión gubernamental, con una forma de gobernar cada vez más personalista y autoritaria. Estas tendencias alejan crecientemente al régimen político venezolano de la institucionalidad liberal que lo caracterizó durante la segunda mitad del siglo XX. Los cambios se sucedieron sobre un escenario socioeconómico caracterizado por un desajuste de la economía y las finanzas públicas, que conllevaron al agravamiento y/o crisis de servicios sociales básicos como el acceso a luz y agua en las ciudades principales $\mathrm{y}$ un deterioro igualmente creciente en los índices de seguridad ciudadana. Esto a su vez impulsó una constante y creciente protesta popular. En el contexto internacional, el desajuste fiscal afectó las políticas de cooperación interamericana del gobierno, bajando el protagonismo de Venezuela y del Presidente en organismos multiestatales latinoamericanos y mundiales e incidiendo en una disminución de la complacencia de otros gobiernos con las actuaciones internacionales y nacionales de Venezuela.

En una primera parte, con el objetivo de entender las orientaciones que guían la gestión gubernamental, presentaremos las principales características del Socialismo del siglo XXI contenidas en el documento oficial titulado Las Líneas Generales del Desarrollo Económico y Social de la Nación 2007-2013 (en adelante LGDESN), que es la denominación que ahora se le da al Plan de la Nación. En una segunda parte, presentamos los principales indicadores socioeconómicos del año. La parte tres describe el proceso electoral realizado el 15 de febrero, que aprobó una enmienda constitucional que permite la reelección indefinida del Presidente y de todos los cargos de elección popular. La cuarta parte recoge los principales hitos de la gestión del Ejecutivo Nacional, el principal actor gubernamental. En la última se señalan desarrollos relevantes del Poder Legislativo y se cierra con conclusiones.

\section{EL SOCIALISMO DEL SIGLO XXI}

Una propuesta de reforma constitucional para reorientar el proceso de cambios en Venezuela con un modelo distinto al de la Constitución de 1999 fue rechazada en referendo popular de 2007 (Álvarez, 2008). El gobierno, sin embargo, prosiguió impulsando los cambios de acuerdo a la orientación rechazada, haciendo uso primero de una Ley Habilitante que estuvo en vigencia hasta mediados de 2008 (Maingón y Welsh, 2009), y luego aprobando leyes en la Asamblea Nacional, donde controla la mayoría calificada. Las LGDESN, que fueron elaboradas de manera coordinada con la propuesta de reforma constitucional rechazada, no fueron modificadas y han seguido orientando la gestión del gobierno. 
Según estas LGDESN -cuya introducción lleva como novedad la utilización de comandante presidente en la firma de Hugo Chávez- el modelo socialista propuesto tiene como directrices: a) la creación de una Nueva Ética Socialista sostenida sobre las corrientes humanistas del socialismo y las nacionalistas de Simón Bolívar; b) la búsqueda de la Suprema Felicidad Social a partir de la construcción de una sociedad incluyente; c) la construcción de una Democracia Protagónica y Revolucionaria, entendida como una que transforma la debilidad del individuo en fuerza colectiva, y d) un Modelo Productivo Socialista, entendiendo por ello la eliminación de la división y jerarquización social del trabajo y la eliminación del criterio de la producción de riqueza subordinada a la reproducción del capital, para ser sustituida por otro que sirva a la satisfacción de las necesidades humanas. Adicionalmente, las LGDESN señalan una modificación de la estructura socioterritorial para ajustarla al nuevo modelo productivo, la utilización del petróleo para convertir a Venezuela en una Potencia Energética Mundial y la promoción de una Nueva Geopolítica Internacional dirigida a la búsqueda de la multipolaridad como orden internacional (pp. 5-6).

Según la directriz de la ética socialista, el primer desafío es superar la miseria y la pobreza material y espiritual mediante la construcción de un Estado ético con funcionarios que exhiban una conducta moral en sus condiciones de vida. En las LGDESN se afirma -claramente influenciado por el pensamiento de Rousseau-que hay valores, principios, que están en la conciencia social "no por un pacto sino por algo que está dentro de cada uno y del corazón social, que lo sentimos como un deber de la humanidad (...)" (p.9). La nueva ética llevará al "hombre nuevo", con el cual se superará la "prehistoria humana" y entraremos a la "verdadera historia", la del socialismo (p. 10).

Según la directriz de la suprema felicidad social, la nueva estructura social incluyente estará basada en formas de propiedad social conteniendo en esta acepción las autogestionada, asociativa y comunitaria (p. 12). Las LGDESN sólo enuncian estos tres tipos de propiedad sin darles definición alguna. En la rechazada propuesta de reforma constitucional en 2007 la propiedad social había sido definida como "aquella que pertenece al pueblo en su conjunto y las futuras generaciones, y podrá ser de dos tipos: la propiedad social indirecta, cuando es ejercida por el Estado a nombre de la comunidad, y la propiedad social directa, cuando el Estado la asigna bajo distintas formas y en ámbitos territoriales demarcados a una o varias comunidades, a una o varias comunas, constituyéndose así en propiedad comunal o a una o varias ciudades, constituyéndose así en propiedad ciudadana" (itálicas nuestras). ${ }^{1}$

En las LGDESN se contemplan además de las anteriores la propiedad pública y la "individual", sin explicar en qué consiste esta última y que pareciera sustituir a la propiedad privada, abriendo un campo de incertidumbres, con lo cual queda ésta de hecho debilitada. La propiedad pública, por su parte, fue definida en la rechazada reforma como perteneciente "a los entes del Estado", configurando una propiedad distinta a la social indirecta y sin aclarar por qué. En la propuesta de reforma sí se 
hizo una alusión directa a la propiedad privada estableciendo que "Se reconocen y garantizan las diferentes formas de propiedad" (propuesta de reforma al artículo 115). En concordancia con estos lineamientos, en los años más recientes el gobierno ha venido estatizando industrias de distinto tipo como parte de su estrategia para la construcción de su modelo. En algunos casos se trata de reestatizaciones, pues durante el período de hegemonía neoliberal fueron privatizadas. Entre éstas se encuentran la Siderúrgica del Orinoco (Sidor) y la Compañía Anónima Nacional de Teléfonos de Venezuela (CANTV). Otras nunca habían sido empresas públicas como la Electricidad de Caracas y Cementos Mexicanos. Cabe señalar que estas estatizaciones se hicieron con el debido pago de indemnizaciones.

Se argumenta en las LGDESN que la transformación de la estructura social en la dirección propuesta es posible por "la nueva forma de utilizar la renta petrolera". Esa renta, a través de su inversión en políticas sociales masivas y aceleradas como las Misiones, permitirá universalizar la satisfacción de necesidades básicas como alimentos, salud, educación, vivienda, empleo e identidad (LGDESN, 2007: 12). Otros objetivos específicos de esta directriz son reducir a cero la miseria para el período hasta 2013, fortalecer la accesibilidad de los alimentos, apoyar la organización y participación de los trabajadores en la gestión de las empresas e incrementar la participación de los consejos comunales en la planificación y control de la economía, así como establecer mecanismos para la socialización de los excedentes (pp. 14-16).

A diferencia de lo consagrado en la Constitución de 1999, que preservando formas institucionales de democracia representativa incorpora adicionalmente formas directas de participación-democracia participativa y protagónica-, en las LGDESN se incorpora la directriz de la Democracia Protogónica Revolucionaria, que se define explícitamente como alternativa a la democracia representativa clásica y aparentemente es distinta también a la participativa y protagónica: "Dado que la soberanía reside en el pueblo, este puede por sí mismo dirigir el Estado, sin necesidad de delegar su soberanía, tal como en la práctica sucede con la democracia representativa o indirecta" (itálicas nuestra, p. 17). En la misma directriz se apunta hacia el debilitamiento de la noción del Estado de derecho: “En la democracia protagónica revolucionaria ... la justicia está por encima del derecho; y las condiciones para garantizar el bienestar de todos, tales como educación, salud y trabajo están por encima de la simple formalidad de la igualdad ante la ley y el despotismo mercantil" (itálicas nuestras, p. 18).

En la directriz sobre el modelo productivo socialista se establecen las llamadas empresas de producción social (EPS), a las cuales se les considera el germen del socialismo del siglo XXI. Se definen como empresas que se dedican a producir bienes y servicios sin los valores capitalistas del egoísmo y la ganancia. En ellas no existen privilegios y hay igualdad sustantiva entre sus integrantes, usan la planificación participativa y protagónica, y el excedente se reparte en proporción al trabajo aportado (p. 25). Estarán apoyadas por la industria petrolera y empresas del Estado productoras de bienes básicos, que delegarán en ellas progresivamente actividades productivas. Asimismo, empresas del Estado, de acuerdo a sus particularidades, se irán transformando en EPS (p. 25). 
El modelo productivo socialista busca consolidar una economía endógena de múltiples encadenamientos productivos internos, diversificando el potencial exportador de bienes y servicios después que se hayan satisfecho las necesidades internas. Propiciará una política comercial cónsona con el desarrollo endógeno y una innovación científica y tecnológica adaptada al objetivo de satisfacer las necesidades humanas. Además de la industria básica energética, se dará prioridad a la producción de alimentos, manufactura y servicios básicos para la población (pp. 26 y 27). Las LGDESN enfatizan la actividad de producción de alimentos dentro de la llamada política de seguridad alimentaria, entendiendo por ello un desarrollo rural integral por considerar que permitiría una reocupación más equilibrada del territorio, la redistribución del ingreso y aportaría las materias primas a la industria. Por tanto, se asienta que se busca culminar una revolución agraria -no una reforma agraria- eliminando el latifundio, invirtiendo durante este período sustantivamente en la agricultura, en especial para riego, saneamiento de tierras y vialidad rural, así como apoyando a los productores en todo lo que requieran: financiamiento, capacitación, maquinaria, insumos, etc. (p. 27). Entre otros de los múltiples objetivos se señala explícitamente el apoyo a la pequeña y mediana industria así como a las cooperativas (p. 30).

Las LGDESN buscan también una reocupación del espacio en Venezuela bajo la idea de un Desarrollo Territorial Desconcentrado, resultado de una planificación integral, que articule la construcción y organización del nuevo modelo productivo endógeno donde emergerán las nuevas relaciones sociales (p. 33). Implica esta directriz un cambio de rumbo con relación a las tendencias de descentralización político-administrativas de las décadas finales del siglo XX que quedaron expresadas en la Constitución de 1999, quedando ahora ausentes en este documento los poderes regionales y municipales.

Finalmente, las Líneas contemplan otras dos directrices: Venezuela Potencia Energética Mundial y Nueva Geopolitica Internacional, donde se reitera el papel clave de la industria petrolera como "corresponsable de primera línea" del nuevo modelo productivo (p. 42), y se hace énfasis en la utilización de los recursos energéticos para la integración latinoamericana y caribeña, y para el fortalecimiento de polos de poder mundial alternativos al "imperialismo norteamericano".

\section{CONTEXTO NACIONAL E INTERNACIONAL}

\section{Coyuntura económica}

En el previo año de 2008 la cesta petrolera venezolana alcanzó un precio promedio histórico de $\$ 89,09$ el barril, trepando en junio de ese año a un precio sin precedentes de \$ 118,98 el barril. Inició luego una caída abrupta que en diciembre llegó a \$31,55. El año 2009 se inició con una primero lenta y luego más decidida recuperación del precio del barril, terminando la cesta venezolana a un precio promedio de $\$ 56,93$, lo que significó una reducción del 36,01\% con relación a 2008. Estos zigzagueos del precio petrolero, producto de la honda crisis financiera internacional, contrajeron el ingreso fiscal, y con ello el gasto público, profundizando la tendencia a la desaceleración del 
crecimiento económico que Venezuela traía desde 2005. El año cerró con una retracción del PIB de $-3,3 \%$ (ver Cuadro 1), registrándose una caída en la actividad petrolera del $-7,2 \%(B C V, 2010)$.

Cuadro 1: Algunos indicadores macroeconómicos y precios de la cesta petrolera venezolana, 2004-2009

\begin{tabular}{lcccccc}
\hline Año & $\begin{array}{c}\text { Variación } \\
\text { PIB }\end{array}$ & $\begin{array}{c}\text { Variación } \\
\text { PIB } \\
\text { Sector } \\
\text { Público }\end{array}$ & $\begin{array}{c}\text { Variación } \\
\text { PIB } \\
\text { Sector } \\
\text { Privado }\end{array}$ & Inflación & $\begin{array}{c}\text { Tasa } \\
\text { de } \\
\text { desocupa- } \\
\text { ción* }\end{array}$ & $\begin{array}{c}\text { Precio } \\
\text { promedio } \\
\text { del } \\
\text { barril }^{*}\end{array}$ \\
\hline 2004 & 18,3 & 12,5 & 17,2 & 19,2 & 15,1 & 32,88 \\
2005 & 10,3 & 2,8 & 12,9 & 14,4 & 12,2 & 46,15 \\
2006 & 9,9 & 2,7 & 11,3 & 17,0 & 10,0 & 56,96 \\
2007 & 8,2 & 7,4 & 7,5 & 22,5 & 8,5 & 65,13 \\
2008 & 4,8 & 16,3 & $-0,1$ & 30,9 & 7,4 & 89,08 \\
2009 & $-3,3$ & 0,9 & $-4,5$ & 25,1 & 7,9 & 56,93 \\
\hline
\end{tabular}

* Promedios anuales.

Fuente: BCV (www.bcv.org.ve), INE (www.ine.gov.ve) y MPPEP (www.mem.gob.ve en base de datos L. E. Lander).

Las penurias fiscales del Petroestado venezolano en 2009, así como las dificultades afrontadas por Petróleos de Venezuela SA (PDVSA), tanto por la baja de los precios como por la reducción de su producción, caracterizaron el contexto socioeconómico del año, recordando ciclos similares de bonanza y declive de los precios petroleros en el mercado internacional que Venezuela vivió en el siglo XX. Los desajustes fiscales se tradujeron una vez más en demoras en el pago de las compras públicas, suspensión o postergación de la construcción de obras de infraestructura, demoras en el pago de salarios, disminución de los recursos destinados a las misiones sociales, suspensión de las discusiones de los contratos colectivos y aumento del endeudamiento público.

\section{Situación social}

Especial mención merece el comportamiento del salario mínimo. El 30 de marzo el Presidente Chávez decretó su incremento en $10 \%$ a partir del primero de mayo y otro $10 \%$ adicional a partir del mes de septiembre para alcanzar un $20 \%$. Como puede verse en el Cuadro 1, la inflación del año 2008 alcanzó el 30,9\% y las del 2009 alcanzaría el $25,1 \%$, con lo cual el incremento del sueldo mínimo, dividido además en dos partes, no llegó a compensar el deterioro de los ingresos ocurrido el año anterior, ni el que ocurriría ese año. Así, el salario mínimo real se ha venido reduciendo por dos años consecutivos. La tasa de desocupación, por su parte, que según las cifras oficiales venía descendiendo sostenidamente, en el año 2009 experimentó un ligero incremento al pasar de 7,4\% en 2008 a 7,9\%. Sin embargo, también según cifras oficiales, tanto la pobreza como la 
pobreza extrema continuaron su tendencia decreciente al pasar el porcentaje de hogares en pobreza de $27,5 \%$ en 2008 a $19,10 \%$ en el primer semestre de 2009 y los de pobreza extrema de 7,6\% a 6,6\% (INE en www.ine.gov.ve, bajado el 16-04-2010).

Relacionado parcialmente con el desempeño socioeconómico, durante 2009 se registró el número más elevado de protestas populares durante los gobiernos del Presidente Chávez. Según Provea, entre octubre de 2008 y septiembre de 2009 fueron contabilizadas 2.893 manifestaciones, de las cuales 2.822 fueron pacíficas y las 71 restantes violentas. Esto representó un incremento de protestas del 64,09\% respecto al período anterior. Continuó también incrementándose la represión a las manifestaciones pacíficas al pasar de una de cada veinte manifestaciones reprimidas en el informe anual anterior, a una de cada quince. Estos datos son indicadores tanto de un creciente malestar social como de una también creciente represión. Durante el ejercicio de derecho a la manifestación pacífica, fueron registradas este año siete defunciones, cinco a manos de funcionarios policiales o militares, y dos por civiles armados (Provea, 2009: 295). Según Provea, la forma de represión más usada es la de someter a juicios penales a personas que participan en manifestaciones, concentraciones y huelgas. Este procedimiento también aumentó en un 35\% con relación a 2008 (p. 297), siendo 676 las personas sometidas a estos procesos.

De acuerdo al mismo informe anual de Provea, continúan también deteriorándose los principales indicadores de seguridad ciudadana. La tasa de homicidios por 100.000 habitantes en el año 2008 fue de 52, habiendo sido el año anterior de 48. Entre octubre de 2008 y septiembre de 2009 se registró un incremento, con respecto al período anterior, de 41,35\% en el número de secuestros denunciados, al pasar de 366 a 518 (p. 349).

\section{Hitos subregionales e internacionales}

El año se inició con un cambio de expectativas en torno a las relaciones de Latinoamérica con EE.UU., al tomar posesión del gobierno el demócrata Barack Obama. En abril tuvo lugar en Puerto España la V Cumbre de Las Américas, con la presencia del novel mandatario y más de treinta presidentes de la región. Hubo un encuentro breve directo entre Chávez y Obama, que pareció vislumbrar la posibilidad de una distensión en las tensas relaciones que caracterizaron las vividas durante la administración del Presidente Bush. Con Obama, el Presidente Chávez perdió a su contrincante privilegiado en el ámbito internacional, dado el talante menos beligerante del nuevo mandatario con relación a su antecesor en la Casa Blanca.

El 28 de junio fue derrocado mediante un golpe militar el Presidente Manuel Zelaya de Honduras. Desde un principio el gobierno de Venezuela y el Presidente Chávez quisieron asumir papeles protagónicos en los esfuerzos por restaurar al presidente hondureño. Sin embargo, la realización de elecciones el 29 de noviembre y la toma de posesión de un nuevo presidente en enero de 2010, sin que Zelaya haya sido restituido en el cargo, puede considerarse un revés de la política venezolana en Centroamérica.

El anuncio en julio del gobierno colombiano de una negociación con el gobierno de EE.UU., para autorizar el uso de siete de sus bases militares dentro de la política de cooperación de ambos en la lucha contra el terrorismo y el narcotráfico, fue un tercer hito 
a destacar este año. En septiembre el Presidente Chávez cortó el comercio con el vecino país, deteriorándose aún más las ya tensas relaciones. Asimismo las expectativas de una mejoría en las relaciones con EE.UU. se vieron menoscabadas. El Presidente Chávez ha usado este incidente como argumentación para continuar y aun profundizar las compras de equipamientos militares que ha venido haciendo en distintos países como Rusia, China y Bielorrusia, dentro del objetivo gubernamental de defender a la "revolución" de sus enemigos. Es también una forma de fortalecer alianzas internacionales que hagan contrapeso a EE.UU. Este año continuaron sus viajes a Cuba, y a otros países de América Latina, a África y al Medio Oriente, con miras a mantener visible su imagen de líder internacional. En esos viajes se firmaron numerosos compromisos de cooperación, muchos de los cuales son inciertos en su desarrollo.

\section{15 DE FEBRERO: REFERENDO DE ENMIENDA CONSTITUCIONAL}

El 23 de noviembre de 2008 se realizaron en el país elecciones para elegir gobernadores y alcaldes. Los candidatos chavistas a las distintas gobernaciones obtuvieron un millón trescientos mil votos más que los candidatos de oposición. Además, en algunos estados, candidatos disidentes del chavismo sumaron más de cuatrocientos mil votos. Estimulado por esos favorables resultados, el Presidente consideró que el momento era propicio para insistir en un tema ya derrotado en la propuesta de reforma constitucional: su reelección indefinida. Apenas unos días luego de esos comicios comenzó a proponer públicamente la idea y la Asamblea Nacional aprobó el 19 de diciembre, en primera discusión, una propuesta de enmienda constitucional. Esa propuesta inicial estaba limitada al cambio de un único artículo, el 230, para eliminar las limitaciones a la reelección del Presidente. El 5 de enero, persuadido de la necesidad de sumar los votos de la mayor parte de la disidencia chavista, Chávez aceptó la idea del partido PPT de ampliar su propuesta para modificar cuatro artículos más de la Constitución y permitir la reelección indefinida de todos los cargos de elección popular. Asimismo continuó presionando para que el referendo fuese lo más pronto posible.

El 14 de enero la Asamblea Nacional aprobó la convocatoria de un referendo para "enmendar" cinco artículos de la Constitución para ser realizado el 15 de febrero. La pregunta que fue sometida a consulta decía así: "¿Aprueba usted la enmienda de los artículos 160, 162, 174, 192 y 230 de la Constitución de la República tramitada por la Asamblea Nacional que amplía los derechos políticos del pueblo con el fin de permitir que cualquier ciudadano o ciudadana, en ejercicio de un cargo de elección popular, pueda ser sujeto de postulación como candidato o candidata para el mismo cargo por el tiempo establecido constitucionalmente dependiendo su posible elección exclusivamente del voto popular?" Para garantizar transparencia y equidad una pregunta sometida a referendo debe ser neutral y no inducir al elector por alguna de las opciones, ésta claramente no lo era.

El triunfo de la propuesta de Chávez fue en términos absolutos y porcentuales bastante claro: con el $54,85 \%$ de los votos válidos, el SI a favor de la enmienda se colocó casi 
$10 \%$ sobre el NO, alcanzando 6.310.482 votos. El NO por su parte obtuvo 5.193 .839 de votos, el $45,14 \%$.

Fue notoria durante el período de campaña la desigualdad de la competencia electoral a favor de la propuesta del Presidente. Se presenció de manera descarnada el uso de los recursos públicos por parte de su parcialidad política, incluyendo el uso de los organismos del Estado. El 7 de enero desde un acto del Comando Simón Bolívar transmitido por cadena nacional de radio y televisión, la ministra del Poder Popular para el Desarrollo Social exhortó a instancias participativas como las mesas técnicas y los consejos comunales a abandonar las obras y dedicarse, de lleno, a buscar los votos para que se impusiese la propuesta del Presidente de permitir la reelección en todos los cargos (El Nacional, 8-1-09). El 15 de febrero, durante la jornada electoral, militantes y simpatizantes del Presidente se presentaban a los centros de votación con propaganda proselitista a favor de la opción del SI. Igualmente se observó el uso de comedores de distintos entes públicos dedicados a proporcionar almuerzos para los militantes de la parcialidad política del Presidente que conformaban las mesas electorales (El Nacional, 16-02-09).

Ojo Electoral, asociación independiente de observación electoral nacional, en su informe sobre el referendo del 15 de febrero presentó sus resultados sobre el seguimiento de la campaña en medios impresos. Allí registró múltiples y variadas violaciones de las regulaciones emitidas por el CNE. Destacan, la abusiva participación de diferentes organismos públicos en la promoción de la opción promovida por el Presidente. Contabilizó que el 16\% de toda la propaganda fue pautada por dichos organismos. Calculando los costos en publicidad en medios impresos, según sus tarifas comerciales, Ojo Electoral determinó que el 71\% de la publicidad fue pautada por el bloque del SI, el 15\% por organismos públicos con publicidad indirecta favorable al SI y sólo el 14\% por el bloque del NO (Ojo Electoral, 2009).

\section{EL PODER EJECUTIVO}

La frecuente rotación de miembros del Gabinete Ejecutivo ha sido una constante en los años de gobierno del presidente Chávez. Más que incorporar nuevas caras, con frecuencia de lo que se trata es de intercambiar personajes de un ministerio a otro. Algunos son desincorporados temporalmente para ser nuevamente llamados al gabinete. El 27 de febrero el ministro del Poder Popular para la Planificación y el Desarrollo, Haiman El Troudi, fue sustituido por Jorge Giordani. Es la tercera vez que Giordani es nombrado para este cargo. A inicios de marzo continuó la reestructuración del Gabinete con otros cambios: Eduardo Samán, fue nombrado ministro del Poder Popular para el Comercio; Jesús María Mantilla Oliveros, ministro para Salud y Protección; Diosdado Cabello para Obras Públicas y Vivienda; Nuri Orihuela Guevara para la Ciencia y la Tecnología e Industrias Intermedias; Erika Farías para Las Comunas; María Cristina Iglesias, Trabajo y Seguridad Social, y Pedro Morejón Carrillo para Turismo. El vicepresidente Ramón Carrizales Rengifo fue nombrado adicionalmente Ministro del Poder Popular para la Defensa. 
En esta reestructuración se fusionaron, eliminaron y cambiaron nombres de ministerios:

Ministerios del Poder Popular (MPP) para:

\begin{tabular}{ll}
\hline \multicolumn{1}{c}{ Denominación anterior } & \multicolumn{1}{c}{ Denominación nueva } \\
\hline Ciencia y Tecnología & Ciencia, Tecnología e Industrias Intermedias \\
Industrias Ligeras y Comercio & Comercio \\
Infraestructura & Obras Públicas y Vivienda \\
Salud & Salud y Protección Social \\
Economía Popular & Las Comunas \\
Vivienda y Hábitat & Eliminado (fusionado con MPPOPV) \\
Participación y Protección Social & Eliminado (fusionado con MPPS) \\
\hline
\end{tabular}

En septiembre el Presidente anunció una reestructuración del Consejo de Ministros, creando seis nuevas vicepresidencias. El vicepresidente ejecutivo, Ramón Carrizales, fue juramentado ahora también como primer vicepresidente del Consejo de Ministros, los ministros Luis Reyes Reyes como vicepresidente social, Jorge Giordani, como vicepresidente económico financiero, Jessie Chacón, como vicepresidente económico productivo, Rafael Ramírez, como vicepresidente para el desarrollo endógeno territorial y el canciller Nicolás Maduro, vicepresidente de política interna e internacional, seguridad y defensa. El Presidente designó a Eugenio Vázquez Orellana como presidente del recién nacionalizado Banco de Venezuela, que fungirá además como encargado de un nuevo ministerio que tendría como fin unificar la banca pública y privada nacional. Finalmente Chávez anunció la designación como secretario permanente del Consejo de Ministros a Freddy Bernal. Dentro de esta reestructuración, el Consejo de Ministros contará con un Consejo Presidencial presidido por Chávez e integrado por los seis vicepresidentes y el secretario permanente (Telesur y VTV, 19-9-2009, bajado de Internet en abril 2010). Finalmente a inicios de diciembre en medio de una crisis bancaria el ministro Jessie Chacón presentó su renuncia luego de la detención de su hermano involucrado en esa crisis. Ricardo Menéndez fue designado para sustituirlo.

De estos nombramientos, para mencionar sólo dos casos, Diosdado Cabello había sido ya vicepresidente, ministro de Infraestructura y gobernador del estado Miranda y María Cristina Iglesias había ocupado anteriormente esa misma cartera y la de Industrias Ligeras y Comercio. Estas rotaciones parecieran obedecer más a criterios de lealtad política al Presidente que a competencias profesionales en el área. Por otra parte, la presencia de militares -activos o en condición de retiro- es siempre numerosa con tendencias a crecer. De los nombramientos mencionados Cabello, Carrizales, Chacón, Mantilla, Morejón y Reyes provienen de la Fuerza Armada. 
Durante 2009, continuando con lo pautado desde 2007 en las LGDESN, siguieron los procesos de concentración de poder económico y político en la Presidencia de la República, manifestándose en nuevas estatizaciones de empresas y expropiaciones de tierras, así como en la profundización de la recentralización del aparato político-administrativo del Estado, debilitando los poderes de gobernaciones y alcaldías. Prosiguió también el deterioro de la autonomía de los otros poderes públicos y su subordinación al Presidente. Estos procesos forman parte de la construcción de lo que el Presidente denomina el modelo socialista del siglo XXI, ya anunciadas en las LGDESN que presentamos arriba, y que procura desmantelar la institucionalidad liberal preexistente.

Hubo una acentuación del ritmo en las estatizaciones y expropiaciones. Como ejemplos de esto podemos señalar: el 28 de febrero el gobierno ordenó la intervención y control militar de empresas arroceras a las que acusó de responsables del desabastecimiento de ese producto, siendo la principal afectada Alimentos Polar. En marzo Chávez ordenó expropiar plantas procesadoras de arroz de la empresa estadounidense Cargill, a la que acusó de violar la ley de producción de alimentos con precios controlados. Ese mes también anunció que la aerolínea Aeropostal, intervenida en noviembre de 2008, se convertiría en empresa de propiedad social. En mayo fueron nacionalizadas 60 empresas de actividades petroleras complementarias (transporte, inyección de agua, vapor o gas) en el lago de Maracaibo. También anunció que había cerrado la negociación con el Grupo Santander para la adquisición del Banco de Venezuela. En septiembre expropió cuatro empresas de transporte de combustibles que operaban en los estados Zulia y Lara. En octubre, decretó la adquisición forzosa del complejo turístico de la cadena Hilton en la isla de Margarita. En noviembre nacionalizó la empresa procesadora de café Fama de América. En diciembre, en medio de un desarreglo bancario con denuncias de corrupción, fueron intervenidas varias entidades bancarias y de seguros, así como algunas empresas vinculadas a las anteriores.

Pueden también mencionarse algunos ejemplos de expropiaciones de tierras. En marzo fueron intervenidas 1.500 ha. de la papelera irlandesa Smurfit Kappa, para cambiarles de cultivo. En abril se ocupó el Hato El Frío y en mayo el Presidente Chávez expropió 10.000 hectáreas de latifundios en distintas partes del país para fomentar la producción de alimentos. Otro ejemplo fue el "rescate" en septiembre de 2.408 ha. del valle del río Turbio, afectando al menos a 30 hatos y justificado por el ministro del Poder Popular para la Agricultura y Tierras porque: "El derecho a la alimentación del pueblo está por encima de la propiedad privada." (Provea, 2009: 178). Cómo todos estos ejemplos ilustran la política de expropiaciones, estatizaciones y nacionalizaciones afectaron las más variadas actividades económicas.

Con relación a la continuación de tendencias de recentralización político-administrativa, luego de las elecciones regionales y locales de noviembre 2008, donde la oposición triunfó en estados cuyos gobernadores anteriores eran chavistas (Carabobo, Miranda y Táchira), ratificó sus triunfos en otros estados (Nueva Esparta y Zulia), ganando además la Alcaldía Metropolitana de Caracas así como las alcaldías de cuatro de los cinco municipios de esa ciudad, desde la Presidencia de la República se comenzaron a impulsar acciones 
tendientes a debilitar a estas autoridades. Ello conllevó la elaboración de normativas y leyes conducentes a socavar las orientaciones descentralizadoras contempladas en la Constitución de 1999. Destacan dentro de esta estrategia la aprobación en la Asamblea Nacional de leyes y reformas a leyes como el caso de la reforma a la ley de Descentralización, que transfirió el control de aeropuertos y puertos de las autoridades regionales al Ejecutivo Nacional. En Carabobo se encuentra Puerto Cabello, el puerto más importante del país, y en Nueva Esparta un aeropuerto internacional, siendo la isla de Margarita el principal atractivo turístico de Venezuela.

Otro caso fue la ley Especial sobre la Organización y Régimen del Distrito Capital, aprobada el 13 de abril (GO 39.156). Con esta ley se creó la figura de un "jefe o jefa" del Distrito Capital (DC), que a diferencia de los gobernadores y alcaldes, que son electos, es de libre nombramiento y remoción del Presidente de la República. Los planes "del órgano ejecutivo del distrito capital" deberán elaborarse en concordancia con el Ejecutivo Nacional y el proyecto de presupuesto será presentado para su aprobación ante el Consejo de Ministros. La prestación de servicios públicos, anteriormente bajo responsabilidad de los gobiernos municipales y el metropoilitano, se hará ahora en coordinación con el Ejecutivo Nacional. No aparece en ninguna parte de la ley de manera explícita la relación de esta nueva instancia de gobierno con la alcaldía del municipio Libertador, siendo que territorialmente el DC y el municipio Libertador son coincidentes. Tampoco con la Alcaldía Metropolitana de Caracas, de la cual el DC es parte. Sí se desarrollan en esta ley, sin embargo, atribuciones y relaciones con las comunas, los concejos comunales y en general con el Poder Popular, inexistente en la Constitución de 1999.

En diciembre, con motivo de los diez años de la Constitución, el Tribunal Supremo de Justicia (TSJ) organizó un foro internacional. En su inauguración la Presidenta de este Poder expresó su desacuerdo con la "división de poderes" al apuntar sobre la necesidad de alejar a las constituciones de los países de la región del modelo liberal. El Presidente Chávez, por su parte, además de manifestar su coincidencia con lo planteado por la Presidenta del TSJ, también expresó su desacuerdo con la idea de "Estado Federal descentralizado", contenida en la carta magna. Dentro de esa concepción explícita de rechazo a instituciones liberales, continuaron los pasos dirigidos al fortalecimiento de la figura presidencial y al debilitamiento y subordinación de los restantes poderes públicos al Ejecutivo. Los ejemplos este año abundan.

En noviembre se desarrolló el proceso de renovación parcial del Poder Electoral con la selección de dos de los cinco rectores del Consejo Nacional Electoral (CNE). Siendo que la Constitución establece en su artículo 296 que dicho consejo: "estará integrado por cinco personas no vinculadas a organizaciones con fines políticos", las dos nuevas rectoras designadas, así como sus cuatro suplentes provienen de las filas del PSUV habiendo sido una ministra y otra parlamentaria. Para poderse formalmente postular, simplemente renunciaron unos días antes a su militancia partidista. Esta designación pone en evidencia no sólo la subordinación del CNE sino también la subordinación de la Asamblea Nacional (AN) que las designó, y el TSJ que con su silencio avaló la designación. En diciembre otro episodio emblemático se dio con la detención de la jueza 
María Lourdes Afiuni, quien fue privada de libertad por haber decidido la liberación del empresario Eligio Cedeño. La detención de Afiuni se produjo poco después de que el Presidente Chávez, en una alocución televisada criticara esa decisión y aseverara que por haberla tomado, la jueza merecía ir presa. A las declaraciones del Presidente, el Ministerio Público procedió con celeridad a detenerla obviando procedimientos legales requeridos. ¿Será esto un ejemplo de lo que debemos entender cuando en las LGDESN se afirma que "la justicia está por encima del derecho"?

En clara contradicción con lo que fueron los años iniciales del gobierno de Chávez, cuando los principales indicadores registrados sobre derechos humanos experimentaron mejorías (Provea, varios años), en este año fue evidente el endurecimiento del Gobierno con todo tipo de manifestaciones de descontento y crítica a su gestión y al proceso de cambios que adelanta. Los sindicalistas, los estudiantes, medios de comunicación con líneas editoriales opositoras y los partidos políticos de oposición han sido los más afectados.

El Gobierno hizo anuncios de su voluntad de promover consejos de trabajadores que fue visto por muchos sindicalistas como un intento de debilitar sus organizaciones. La discusión de contrataciones colectivas con el Estado y empresas dependientes de él fueron retrasadas de manera sistemática. Según Provea, la violencia en el ámbito sindical repuntó significativamente, registrándose el homicidio de 46 dirigentes sindicales, sin que las investigaciones adelantadas determinaran las responsabilidades de estos actos, manteniéndose una flagrante impunidad.

Las movilizaciones estudiantiles promoviendo el voto negativo en el referendo de la enmienda constitucional fueron respondidas en varias oportunidades por las autoridades con represión. El 17 de enero el Presidente en una alocución televisada mandó a los cuerpos de seguridad a enfrentar "sin diálogo" y con "gas del bueno" las protestas estudiantiles. En septiembre fue detenido por protestar contra la ley de Educación el estudiante de la Universidad Humboldt de Carabobo, Julio César Rivas. La Fiscalía le imputó cinco delitos: resistencia a la autoridad, uso de arma genérica, instigación a la guerra civil, instigación a delinquir y daños y asociación para delinquir. A finales de septiembre fue liberado, después de que un grupo de estudiantes de distintas universidades se instalaron frente a la OEA y realizaron una huelga de hambre que llevaba cuatro días.

Otros casos emblemáticos de amedrentamiento a fuerzas de la oposición este año serían la privación de libertad al ex ministro de Defensa general Raúl Isaías Baduel, acusado de corrupción administrativa durante el ejercicio de su cargo. El general estaba siendo juzgado en libertad pero se decidió recluirlo. En la segunda quincena de agosto fue privado de libertad el prefecto de Caracas y presidente del partido opositor Alianza Bravo Pueblo, por supuestos hechos violentos ocurridos durante una marcha de los empleados de la Alcaldía Metropolitana de Caracas en rechazo a la ley Especial del DC.

Las acciones contra medios de comunicación privados con miras a ampliar el control mediático del Gobierno fueron múltiples. Entre éstas, el canal de TV opositor, Globovisión, fue sometido a varios procedimientos administrativos con el argumento de que violaba la ley de Responsabilidad Social de Radio y Televisión. Luego de un Aló Presidente en el 
que Chávez fustigó a los medios de comunicación privados, el 11de mayo el Ministerio del Poder Popular para las Telecomunicaciones y la Informática autorizó a CONATEL mediante una resolución publicada en Gaceta Oficial (39.175) a inspeccionar a las empresas del sector de telecomunicaciones, a fin de verificar la instalación, operación y prestación de servicios. A inicios de agosto, treinta y cuatro emisoras de radio fueron sacadas del aire mediante procedimientos "legales". El Presidente Chávez había declarado con anterioridad que la revisión hecha por CONATEL había "descubierto" que "centenares" de emisoras radiofónicas funcionaban de manera ilegal. Anunció que serían sacadas del aire y traspasadas sus frecuencias a emisoras afines al gobierno: "Esas emisoras nuevas que se van a crear (...) no son para dárselas a la burguesía, hay que crear una radio popular en manos del pueblo".

\section{EL PODER LEGISLATIVO}

Desde la aprobación de la Constitución de 1999, Venezuela cuenta con cinco poderes públicos autónomos e independientes entre sí. Además de los tres poderes clásicos están el Poder Ciudadano, conformado por la Contraloría, la Fiscalía y la Defensoría del Pueblo, y el Poder Electoral. Sin embargo, como hemos venido desarrollando, la dinámica de los años recientes ha venido concentrando poderes en la Presidencia de la República, subordinando los demás poderes y debilitando su autonomía e independencia. A continuación mencionaremos algunos hitos y actuaciones de la AN que estando inmersos en la dinámica señalada consideramos no obstante relevantes de destacar como complemento a lo ya desarrollado con relación al CNE, al TSJ y a la Fiscalía.

Como resultado del retiro de los partidos de oposición en las elecciones parlamentarias de 2005, la composición de la actual AN inicialmente fue cien por ciento pro oficialista. A pesar de que se han producido algunas disidencias desde entonces, el oficialismo mantiene una mayoría que supera las dos terceras partes (ver gestión 2008, Maingón y Welsh, 2009). En enero de 2009 fueron electos como Junta Directiva para este período de sesiones los diputados: Cilia Flores (presidenta), Saúl Ortega (primer vicepresidente) y José Albornoz (segundo vicepresidente). La holgada mayoría de la que dispone el oficialismo les permitió aprobar leyes ordinarias y leyes orgánicas sin mayor deliberación ni debate, siguiendo las orientaciones emanadas del Ejecutivo Nacional.

Durante este período fueron aprobadas las siguientes nueve leyes orgánicas: la ley de Reforma Parcial de la ley Orgánica de Descentralización (GO 39.140) ya señalada, ley de Reforma Parcial de la Ley Orgánica del Poder Público Municipal (2-4-09), ley Orgánica que Reserva al Estado Bienes y Servicios de las Actividades de los Hidrocarburos (GO 39.173), ley Orgánica de Educación (GO 5.929 Extraordinario), ley Orgánica de Procesos Electorales (GO 5.928 Extraordinario), ley de Reforma Parcial del Código Orgánico Procesal Penal (GO 37.022 ), ley de Reforma Parcial al Decreto N 6.239 con Rango, Valor y Fuerza de Ley Orgánica de la Fuerza Armada Nacional Bolivariana (GO 5.993 Extraordinario), ley de Reforma Parcial a la ley Orgánica de Administración Financiera del Sector Público (GO 39.164) y ley Orgánica de los Consejos Comunales (GO 39.335). 
La modificación de la ley Orgánica del Poder Público Municipal se hizo con la finalidad de posponer las elecciones de concejales y juntas parroquiales para 2010. En la ley Orgánica de Procesos Electorales se introdujo una modificación sustancial del sistema político venezolano. La nueva ley eliminó todo vínculo entre los diputados electos nominalmente de aquellos electos por lista y redujo el número de diputados electos por listas de $40 \%$ a 31,5\%. Esto trae como resultado el pasar de un sistema de representación proporcional consagrado en la Constitución en su artículo $\mathrm{N}^{\circ} 63$ y otros, a un sistema cuasi-mayoritario (ver Ojo Electoral, 2009). La ley Orgánica de los Consejos Comunales, por su parte, continuó profundizado la tendencia a desvincular estas modalidades participativas de los gobiernos municipales para fortalecer sus lazos con el Ejecutivo Nacional como parte del proceso de recentralización político-administrativo que hemos venido señalando. Mientras que en 2002 la ley de los Consejos Locales de Planificación Pública contemplaban a los consejos comunales en un papel activo en la elaboración y seguimiento de los planes de las juntas parroquiales y gobiernos municipales, en esta ley aparece la instancia municipal sólo mencionada cuatro veces en referencia a exenciones de tributos, como una fuente de recursos y en tareas de planificación y presentación de proyectos dentro del Plan Nacional Simón Bolívar.

Fueron aprobadas además de estas leyes orgánicas las siguientes leyes ordinarias: ley de Aeronáutica Civil, ley General de Puertos, ley del Sistema de Justicia, ley Contra el Secuestro y la Extorsión, ley de Reforma Parcial de la ley de Contrataciones Públicas, ley de Beneficios y Facilidades de Pago para las Deudas Agrícolas de Rubros Estratégicos para la Seguridad Alimentaria, ley de Crédito para el Sector Turismo, ley para el Poder Popular de la Juventud, ley de Tierras Urbanas, ley de Conscripción y Alistamiento Militar, ley Especial de Supresión y Liquidación de Corpovargas, ley Especial de Supresión y Liquidación del Instituto Autónomo Fondo Único Social, ley de Extinción de la Acción Penal y Resolución de las Causas para el caso del Régimen Procesal, ley de Simplificación de Trámites para las Exportaciones e Importaciones de las Empresas del Estado, ley para la Prohibición de Video Juegos Bélicos y Juguetes Bélicos, ley del Estatuto de la Función Policial.

\section{CONCLUSIONES}

El año 2009 fue intenso en cambios institucionales y sociopolíticos impulsados desde la Presidencia de la República con el explícito propósito de acelerar las transformaciones del Estado, de la sociedad y de las relaciones entre ambos de acuerdo al modelo socialista dibujado en la rechazada reforma constitucional de 2007 y en las LGDESN que se elaboraron al mismo tiempo y en concordancia con ésta. La combinación de esta transformación impuesta desde arriba con un contexto socioeconómico internacional y nacional signado por indicadores recesivos, nutrió este año un creciente malestar social y político que se expresó de diversas maneras. A ese malestar se añadió la ineficiencia de un aparato estatal cada vez más grande por las políticas de estatización, nacionalización y expropiaciones. Fueron crecientes las denuncias por corrupción, siendo la más relevante la que se reveló en la crisis bancaria de diciembre. En razón de todo esto, la protesta de calle siguió su 
curso ascendente, mientras fuerzas políticas de oposición continuaron sus esfuerzos por construir una plataforma política alternativa que sea creíble para sus bases y para los descontentos de las filas del oficialismo. Sus metas más inmediatas se centran en alcanzar acuerdos entre ellos para presentar al electorado en las elecciones parlamentarias a celebrarse en septiembre de 2010 candidatos unitarios atractivos que puedan llegar a la AN y romper la dominación aplastante que hoy detenta el oficialismo.

La tarea no es, sin embargo, fácil. La polarización política ha devenido en algo más que una estrategia de actores políticos confrontados. Hoy puede considerarse una estrategia gubernamental y en general es un estilo de gobierno que divide a la sociedad y no permite la diversidad ni el pluralismo. Asimismo, la reforma del sistema electoral para convertirlo en uno cuasi-mayoritario favorece a la primera minoría, posición que hasta ahora ocupa el Partido Socialista Unido de Venezuela, el partido del Presidente Chávez. Si a ello se aúna la concentración de recursos económicos y poder político en el Ejecutivo Nacional, el estilo personalista del Presidente, el uso de los recursos públicos para su parcialidad política, la subordinación de los otros poderes públicos a sus designios y el debilitamiento en general de la sociedad vis a vis el Petroestado, el desafío se presenta de grandes proporciones. Mientras tanto, el proyecto político del socialismo del siglo XXI sigue entre dificultades y resistencias en la sociedad su proceso de consolidación.

\section{REFERENCIAS}

Álvarez, Ángel (2008). “Venezuela: ¿La revolución pierde su encanto?"; Revista de Ciencia Política, Vol. 28, $\mathrm{N}^{\circ} 1$, pp. 405-432.

BCV (2010). Tomado de www.bcv.org.ve, bajado en abril.

INE (2010). Tomado de www.ine.gov.ve, bajado en abril.

LGDESN 2007-2013 (2007). Líneas generales del Plan de Desarrollo Económico y Social de la Nación 20072013, Caracas, septiembre, tomado de http:/ / www.gobiernoenlinea.ve/ noticias-view/shareFile/ lineas_generales_de_la_nacion.pdf, bajado en mayo 2009.

Maingón, Thaís y Friederich Welsh (2009). "Venezuela 2008: hoja de ruta hacia el socialismo autoritario"; Revista de Ciencia Política, Vol. 29, No 2, pp. 633-656.

Ojo Electoral (2009). Comunicado de Ojo Electoral ante la Ley Orgánica de Procesos Electorales, tomado de http://www.ojoelectoral.org/comunicados.php bajado en mayo de 2010.

Ojo Electoral (2009). Informe final. Observación referendo de la propuesta de enmienda constitucional, tomado de http:/ / www.ojoelectoral.org/comunicados.php bajado en abril de 2010.

Provea (2009). Situación de los derechos humanos en Venezuela. Informe anual octubre 2008/septiembre 2009. Caracas, Provea. 
Margarita López Maya. Historiadora, doctora en Ciencias Sociales por la Universidad Central de Venezuela (1995). Profesora titular del Centro de Estudios del Desarrollo (Cendes) de la misma universidad. Fue directora de la Revista Venezolana de Economía y Ciencias Sociales entre 1999 y 2004 y miembro del Comité Directivo del Consejo Latinoamericano de Ciencias Sociales (CLACSO) (20072009). Su campo de investigación y docencia es el proceso histórico y sociopolítico contemporáneo de Venezuela, concentrándose en años recientes en el estudio de la protesta popular, los nuevos partidos y actores sociales y temas de coyuntura política. Ha recibido diversos premios académicos, publicado varios libros, numerosos capítulos en libros latinoamericanos y nacionales y más de 60 artículos en revistas académicas. Conferencista en múltiples universidades nacionales e internacionales, ha sido profesora invitada del Kellogg Institute de la Universidad de Notre Dame, Andrés Bello Fellow del St. Antony's College de la Universidad de Oxford, Edward Larocque Tinker Professor de la Universidad de Columbia y Fellow de la Woodrow Wilson International Center for Scholars. Entre sus publicaciones destacan: "Hugo Chávez Frías: su movimiento y presidencia", en Steve Ellner y Daniel Hellinger, La política venezolana en la era de Chávez. Clases, polarización y conflicto (Nueva Sociedad, 2003), Del viernes negro al referendo revocatorio (Caracas, Alfadil, 2005, 2006, 2a edición), Ideas para debatir el socialismo del siglo XXI, tomos I y II (editora, Caracas, Alfadil, 2007 y 2009).

Luis E. Lander. Ingeniero Mecánico venezolano, con estudios de Doctorado en Ciencias Sociales de la Universidad Central de Venezuela (UCV). Profesor de la Facultad de Ciencias Económicas y Sociales (FACES) de la UCV. Ha publicado más de 60 capítulos de libros y artículos en revistas académicas nacionales y extranjeras. Editor del libro Poder y Petróleo en Venezuela (2003). Miembro del comité editorial de la Revista Venezolana de Economía y Ciencias Sociales de Faces - UCV desde 1999, siendo su director entre 2004 y 2007. Conferencista invitado en varias universidades nacionales y extranjeras. Desde 2006 forma parte de la Junta Directiva de la Asociación Civil Ojo Electoral. 
